\title{
Blockchain Technology Application for Value-Added Tax Systems
}

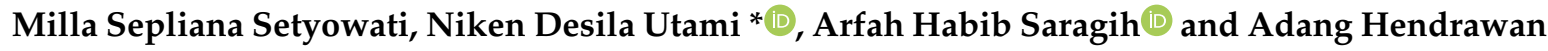 \\ Department of Fiscal Administration, Faculty of Administrative Sciences, Universitas Indonesia, \\ Depok 16424, West Java, Indonesia; milla.s@ui.ac.id (M.S.S.); arfah.habib11@ui.ac.id (A.H.S.); \\ a.hendrawan@ui.ac.id (A.H.) \\ * Correspondence: niken.desila@ui.ac.id
}

Received: 9 October 2020; Accepted: 9 November 2020; Published: 18 November 2020

check for updates

\begin{abstract}
The utilization of new technology in the form of blockchain technology for a Value Added Tax (VAT) acceptance system is relatively new and has not been widely encountered thus far. This research analyzes how blockchain technology can be applied to a VAT system, particularly for electronic invoices (e-Invoice). A qualitative approach was used in this study to analyze blockchain technology models that could be applied in a VAT system. The results of this study indicate that due to its characteristics, blockchain technology can only be applied to taxpayer data that do not require privacy. Data that are considered safe if distributed to nodes in the blockchain technology network include the Tax Invoice Serial Number (TISN). A TISN system based on blockchain technology will produce a faster and more efficient system. Transactions on the TISN in Indonesia can also be monitored and tracked directly by the Directorate General of Taxation (DGT). Blockchain technology can be applied in the TISN system by using a permissioned private blockchain type.
\end{abstract}

Keywords: blockchain technology; e-Invoices; taxation; Value Added Tax (VAT)

\section{Introduction}

Currently, all countries are entering the era of industrial revolution 4.0, where almost all aspects of human life are facilitated by technological developments. The rapid development of technology brings new innovations that will provide vast potential for growth in businesses and markets. If countries do not move quickly in adapting and following the flow of digital trends, they will experience a lag in various government sectors, infrastructure, and society. However, if the era of industrial revolution 4.0 is carefully prepared for, then positive impacts, such as an increased speed of information development, higher productivity, and increased ease of access to information will be obtained [1]. Therefore, these opportunities must be put to good use, especially by developing countries, to improve the economy and the welfare of the people.

The economy and people's welfare can be improved because the increasing flow of trade transactions between businesses and their counterparties results in a greater potential for governments to obtain tax receipts. The taxation sector is one of the sectors that must adapt itself to the industrial revolution 4.0 era to improve the economy and the people's welfare. The Organization for Economic Co-operation and Development (OECD) states that rapid technological advances, digitization, and business patterns have led to continuous transformation and adjustment in tax systems [2].

As one of the largest sources of state revenue, the tax sector should always be able to adapt to any developments that could occur. The type of tax that needs to be considered in the industrial revolution 4.0 era is a tax on consumption, which is commonly called a Goods and Services Tax (GST) or Value Added Tax (VAT). This type of tax provides a significant contribution to government revenues because it is accrued for community and business activities. Therefore, GST or VAT performance will affect 
the tax performance of a country. One indicator for assessing the VAT performance is the VAT ratio, which is calculated by dividing the realization of VAT receipts by the Gross Domestic Product (GDP) over a given period [3].

In this study, we used Indonesian data for an analytical framework. However, because the focus of this research is on the development of blockchain applications in a type of VAT administration system that is widely implemented in other countries, this study can be of broad use to other countries that use this VAT system for collecting taxes on consumption. Based on data from the Indonesian Central Bureau of Statistics (2019), the collection of VAT revenue compared to Indonesia's GDP tended to be low over the period 2014-2017. Indonesia's VAT ratio was at its highest for this period in 2014 at 3.87\% and at its lowest in 2016 at 3.32\%. One of the causes for a low VAT collection rate is the absence of an efficient VAT administration system [3]. The inefficiency of a VAT system makes identifying fictitious tax invoices more difficult and undermines the inability to reach the maximum performance that VAT technology can provide. With Indonesia's entry into the industrial revolution 4.0 era, its government must utilize and develop VAT administration digital technology infrastructure to solve this problem. Therefore, it is necessary for the government to pursue new strategic measures, one of which is to develop new technologies.

One of the new technologies that is in development today is blockchain technology. This technology can provide guaranteed transparency, accuracy, and data security for all relevant parties. It allows authorized public users and controlled users to use its distributed ledgers, as well as to participate in transactions that can be approved by the parties involved. When a transaction has been completed, no party can change its transaction records [4]. Blockchain technology allows peer to peer interactions to occur. Its characteristics, such as autonomy, equality, and transparency, have the potential to detect both corruption and fraud [5].

Apart from that, blockchain technology also provides benefits in terms of data veracity, data security, and data inter-operationality [6]. Another advantage of blockchain technology is that its dimensions, i.e., decision rights, accountability, and incentives, are in line with the literature on good Information Technology (IT) governance [7]. The most important blockchain features for supporting competitive performance are traceability and immutability [8].

The challenges and barriers to adopting blockchain technology include issues of usability and security, legal issues, conflicts of values, and criticism of its political dimensions [9]. The features and challenges of blockchain technology can also explain that there are some business models going to apply blockchain technology in the future [10].

Several previous studies have shown that blockchain technology has been widely applied in various sectors, including both government [11] and business sectors [12]. The fields of accounting, finance, and auditing have benefited greatly from the presence of blockchain technology [13]. In addition, blockchain technology can also be applied for effective and efficient tax administration, for example in the context of VAT. The use of technology provides a much more efficient message transfer mechanism between different parties [14]. Blockchain technology provides a reliable ledger, meaning no party will be able to manipulate it because every transaction in the system will always be retained through the smart contract, and because it provides transparent records.

These are the two reasons why this technology has shown promise for being applied to the VAT system in Saudi Arabia [15]. However, several matters need to be considered for the successful adoption of blockchain technology in VAT systems. Notably, there are at least four alternatives that can be considered and used by governments in the utilization of electronic technology to develop VAT systems. These alternatives include developing regulations and legal products, creating databases and developing infrastructure as the main means of support in the implementation of electronic information and technology in the tax system, developing technical equipment, and developing database software used for efforts to increase the ability of tax authorities to carry out their tax obligations [16].

Blockchain technology makes VAT taxable and charged in real time under the direct supervision of tax authorities [17]. Automation compliance on blockchain technology enables the verification 
and automation of tax filing [18], which could significantly reduce the risk of tax avoidance, fraud, and evasion [19]. Blockchain technology can transparently confirm, verify, and track e-Invoice and e-Nofa. With strong transparency, this technology can also ensure that it will be difficult or even impossible for the parties involved in the chain of administration to commit fraud [20]. However, despite its potential, blockchain technology is not yet widely known by the public nor utilized by the government.

Based on the discussion above, this study focused on the adoption of blockchain technology in the VAT system. Therefore, the purpose of this study is to analyze how blockchain technology models can be applied in the VAT system, particularly in the e-Invoice system. There is currently not much research on the application of blockchain technology in the taxation sector. The utilization of new technology, namely blockchain technology, in the Value Added Tax (VAT) acceptance systems is relatively new and has not yet been widely implemented today. As studies regarding the implementation of blockchain technology in the VAT system are few, this study is expected to provide an overview and a reference for other countries that are planning to adopt blockchain technology to build their GST or VAT systems.

This research has academic and practical contributions. Reviewed from an academic angle, this research is expected to complement similar previous studies related to the development and utilization of new technologies for VAT systems i.e., blockchain technology. As all countries are entering the era of the industrial revolution 4.0, blockchain technology is growing and gaining more attention, particularly in developing countries.

This technology enhances the transparency, accuracy, and data security of VAT systems related to tracking e-Invoice and TISN delivery through e-Nofa. The literature review in this study discusses the application of blockchain technology for both the government and taxation sectors but some of the references do not focus on providing an idea of how blockchain technology can be applied in VAT systems. Thus, the novelty of this research lies in the in-depth description of the application of blockchain technology in a VAT system, particularly in terms of e-Invoice issuance. We hope that this study will provide additional information as well as a reference for other researchers who desire to conduct research on similar topics in the future.

In terms of practical contributions, this research can provide information and input to related parties, including the government and policymakers, i.e., the Directorate General of Taxation (DGT), the Fiscal Policy Agency, the Ministry of Communications and Information Indonesia, and the Center for Financial Information Systems and Technology Ministry of Finance Indonesia, which are directly related to the application of technology in the VAT system. We hope this research can be used as a reference and be considered by the government and stakeholders when making policies related to the application of blockchain technology in VAT systems in Indonesia or other countries.

This paper starts with an introduction that explains the background, purpose, and the academic and practical contributions of this research. Next, the theoretical review contains a literature review of relevant studies and the theoretical framework used in this study. This is followed by the research methodology, which describes the qualitative research method used and the data collection through in-depth interviews. The next section presents the results and discussion, which addresses the application design of blockchain technology on the VAT system and the views of the government, academics, practitioners, and associations regarding the application of blockchain technology in VAT systems. The conclusions of the research are presented at the end of the article.

\section{Theoretical Review}

\subsection{Blockchain Technology}

A blockchain consists of several blocks that merge and link to each other until a block "chain" is formed [21]. Each block identifies the previous block using a hashing function that forms a single unbroken chain set [22]. When a piece of information has already been recorded in the blockchain database, it is difficult to delete or modify that data [23]. The blockchain uses a decentralized and 
distributed ledger method referred to as a distributed ledger. A distributed ledger is a record that contains all transactions in a network and can be accessed by all parties in the network [24].

As a result, there is no administrative control center governing the data in a blockchain network. Any data or information available will be distributed both privately and publicly to servers in the blockchain network. There are two networks in the blockchain, permissioned and permission-less. The permissioned blockchain causes access to transaction details to be restricted to a limited number of parties. Unlike the permissioned blockchain, every participant in the network has access to all the details of a conducted transaction. Blockchain technology provides security, trust, data integration, and anonymity without having to involve third party organizations [25].

The ledger method generally stores the database in a single system with centralized data storage and processing. The ledger method used in the blockchain is a distributed ledger whose data storage system is peer to peer (P2P). These conditions mean that there is no administrative control center that manages the data in the blockchain network. There is a difference between a centralized ledger system and a decentralized ledger system in a blockchain. In a centralized ledger, all data are stored in storage, so that each party on the network must submit and retrieve data in the storage separately. The decentralized ledger system in the blockchain allows all servers to access data in the P2P blockchain network directly (in real time) [22]. The following are the four basic concepts that must be understood before studying blockchains any further [21]:

a. Shared Ledger

A shared ledger is a record that contains all transactions in the blockchain network and can be accessed by all parties on the network [21]. The shared ledger is immutable because it records all transactions from the beginning until the end. The data recording of transactions in a shared ledger is done only once. After this, it is distributed to all parties on the blockchain network, so that they all have a copy of the same data. Thus, it can be said that a shared ledger is a recording system that plays a major role as a trustee in the blockchain network.

\section{b. Permissions}

Permissions are access for parties who intend to enter the private blockchain network. There are two networks on the blockchain, private (permissioned) and public (permission-less) networks. Permissioned blockchain causes each participant to have a unique identity that is different from one another. This identity allows each participant to enter the blockchain network and access existing transactions [21]. Therefore, the permissioned blockchain makes data consistency monitoring more effective. This effectiveness can be achieved because access to the transaction details is limited to only a few parties. Unlike the permission-less blockchain, every participant on the network has access to all the details of the transactions in the blockchain network. To increase the level of security and protect anonymity, the transaction details displayed on the permission-less blockchain can be limited.

\section{c. Smart Contracts}

Smart contracts are stored and executed automatically in the blockchain as part of a transaction. A smart contract is essentially the same as an ordinary contract made on a piece of paper in the real world. The main difference is that smart contracts are digital. The purpose of smart contracts is to provide a better security system than the traditional paper contract [21]. The storage of smart contracts on the blockchain causes all statements in the contract to be distributed to all parties on the blockchain network. If there are provisions that violate the contract, there is no need for a third party to conduct a review. This means that the use of smart contracts eliminates the need for a third party on the blockchain network. Smart contracts can be trusted because they have several characteristics that are immutable and distributable. Immutable means that they cannot be changed, while distributable means that the contents of the contracts will be distributed to all parties in the blockchain network so that they can be validated immediately. 


\section{d. Consensus}

Consensus is an agreement made among all parties in a blockchain network regarding data validation. Data replication and distribution causes the need for data validation by each node so that the data in the block is valid and can be added to the blockchain network. Consensus eliminates the need for third party intervention to run the blockchain system [26]. This proves that blockchain technology is safe, verifiable, and authenticated [21]. The consensus mechanism implemented in blockchain makes this technology less susceptible to fraud.

A blockchain consists of three core parts [23] as follows: (1) The block is the entire list of transactions in the blockchain network which will be stored in the ledger. Each block in the blockchain network has different sizes and periods. (2) The chain is a chain that connects one block to another. Thus, the role of chains is to form links between blocks in the blockchain network. (3) The network is a network consisting of all nodes. The nodes act as a network safeguard containing a complete record of the data of all transactions that have been recorded in the blockchain network.

These three things are a core part that form the structure of the blockchain. In addition, Wijaya and Darmawan [26] asserted that blockchains consist of three types, namely public, consortium, and private. This is in line with the explanation given by [27] that, based on the nature of data accessibility, blockchains can be categorized into three types as follows:

a. Public Blockchain

A public blockchain is a type of blockchain that can be easily accessed by the public. Everyone can check and verify transactions directly in the public blockchain network and can also participate in the process of obtaining consensus [27]. The openness of the network causes the data that exists in the public blockchain network to be very accessible and transparent. Wijaya and Darmawan [26] stated that there are several advantages in the public blockchain that can be improved, tested, and accessed by those who are capable. Since the public blockchain does not use a centralized server system, blockchain security and trust are guaranteed with cryptographic verification.

\section{b. Consortium/Hybrid Blockchain}

A consortium/hybrid blockchain is a distributed ledger whose consensus process is controlled by a set of previously selected nodes [22]. This leads to the fact that not all nodes in the blockchain network can have consensus rights in that network. Parties entitled to read and enter transactions into the network in the consortium/hybrid blockchain are several organizations that have been predetermined and form a joint association together [28].

\section{c. Private Blockchain}

A private blockchain is a type of blockchain whose data are stored centrally in a single organization. Permission to read data or information in the network may be public or limited to a designated group of parties only [22]. Each node or user in the blockchain network will be restricted so that there is strict management authority in that network. This tight data management causes not all nodes to participate in the blockchain network [27]. Thus, it can be stated that node membership in the private blockchain network is controlled and not free to access blocks. In this type, only certain parties can read or submit transactions i.e., an organization or a subsidiary in the same group [28].

The application of blockchain technology in the VAT system in Indonesia will have implications for the optimization of the electronic VAT system. Blockchain technology can be applied in the TISN award system from the DGT's to the Taxable Enterprise (TE). The implementation of blockchain technology in the TISN system makes the system performance faster and reduces the number of stages that must be completed by the TE due to system automation. The application of blockchain technology causes the positions of TE and DGT to be equal, resulting in no TISN requests from all TEs to one DGT server. With a more distributed system and a peer-to-peer network, the TISN system can be faster and 
more efficient. The provisions for TEs to take the TISN themselves can be regulated by the DGT as the smart contract authority. In the smart contract, it can be stated that the DGT retains full power to supervise and check transactions.

\subsection{Value Added Tax (VAT)}

A VAT is a tax imposed on the consumption of goods and services carried out in the customs area [29]. As a type of indirect tax, one of the characteristics of VAT is the multilevel stage where VAT is imposed on each chain of taxable goods (TG) or taxable services (TS) production and distribution lines [30]. The VAT calculation method is the crediting of Input Tax done by reducing tax on the acquisition of taxable goods or taxable services (Output Tax) with tax on the submission of taxable goods or taxable services (Input Tax). At the time of submission of taxable goods or taxable services subject to VAT, there is proof of tax voting called a tax invoice. Both the seller and the buyer can make tax credits if they have [31] received a tax invoice containing the information that must be included in the tax invoice [24]. The obligation to make tax invoices is not related to the payment. As long as taxable goods or taxable services have been submitted by a TE to the counterparty of the transaction then the tax debt will arise thus causing the TE to make a tax invoice as proof of the tax collection owed [30].

VAT has several positive characteristics, namely the legal characteristics of the Indonesian VAT [30]. It has eight legal characteristics, which need to be explained to understand the mechanisms for imposing taxes on the consumption of goods and services.

\section{a. VAT is an Indirect Tax}

An indirect tax is a tax whose imposition can be borne by other parties. The transfer of charges from the seller to the buyer can be made because the tax imposed is not attached to the subject but to the object. This indicates that there is a difference in position between the party bearing the VAT burden and the party responsible for paying the VAT to the state treasury. Buyers and sellers have different positions in the VAT system. The buyer as the party that receives the TG or TS is the one that bears the VAT burden, while the seller TE that provides the TG or TS acts as the party responsible for paying the VAT to the state treasury [30]. The difference in that position occurs to provide legal certainty to all parties, namely the buyers and sellers of TG or TS. Thus, it can be said that the obligation to pay VAT is not directly imposed on the buyer but on the seller.

\section{b. VAT is an Objective Tax}

An objective tax is a tax imposed on a tax object without considering the condition of the taxpayer as a tax subject [31]. Thus, the imposition of VAT does not take into consideration the ability of the tax subject to pay VAT. It can be said that VAT is imposed whenever there is a tax object that can be subject to VAT [21]. The characteristic of VAT as an objective tax causes a regressive impact. Regressive VAT is a gap in the imposition of tax burdens, in which the higher the consumer's ability, the lower the VAT burden will be and vice versa. This regressive VAT occurs because it has a single rate, which is $10 \%$ and does not consider the subjective conditions of the tax subject. Thus, the tax subject still must pay VAT when consuming TG or TS [32] whether they are rich or poor.

\section{c. VAT has a Multi-stage Levy Characteristic}

Multi-stage levy is one of the advantages of VAT. The purpose of the multi-stage levy is to collect VAT at each stage of production and distribution of TG or TS. The imposition of VAT is carried out at each stage of the production and distribution line (multi-stage tax) [31]. The imposition of VAT at each stage of the production and distribution lines shows that VAT is imposed repeatedly on consumers, but for this repetition, the tax is not accumulated so that it will not cause double taxation [30]. 


\section{d. VAT uses Indirect Subtraction/Credit/Invoice Method}

The indirect subtraction method is a method of calculating VAT by deducting taxes on the acquisition of TG or TS (Output Tax) with taxes on submission of TG or TS (Input Tax) [31]. Taxpayers (known as TE in Indonesia) can use the Input Tax or Output Tax credit method in every purchase or sale of a TG or TS transaction. Based on this, Indonesia's VAT adopts the indirect reduction method. This characteristic illustrates that the tax payable is obtained from a reduction between the Output Tax and the Input Tax.

\section{e. VAT is Non-cumulative}

The indirect subtraction method is a method of calculating the VAT by deducting taxes on the VAT is non-cumulative even though it has multi-stage levy characteristics due to the Input Tax crediting mechanism. Non-cumulative means that, even though it is subject to repeated taxes payable in each production and distribution stage, it is not accumulated. This causes the imposition of double taxation and an anti-cascading effect. The noncumulative nature of VAT is a kontradiksio in terminis, which is a figure of speech that means denying the provisions in general [30].

\section{f. VAT uses a Single Rate}

The Indonesian VAT uses a single rate, which is $10 \%$ for domestic delivery and $0 \%$ for TG exports. Single rates have both positive and negative aspects. The positive side is that it is simple, while the negative side is that it can provide sharper regression [30]. Even so, the government can still raise or lower these rates.

\section{g. VAT is a Domestic Consumption Tax}

Indonesian VAT is a tax on domestic TG or TS consumption (customs) according to the destination principle so that it is neutral in the context of international trade [30]. The purpose of the principle of destination is that taxes are imposed only at the place where the TG or TS will be consumed [33]. The VAT will not be charged if the TG or TS is consumed outside the country or outside the Indonesian customs area, which comprises the entire territory of the Republic of Indonesia. Therefore, the place where TG or TS consumption occurs is an important factor in imposing VAT.

\section{h. Indonesian VAT is a Consumption Type VAT}

A consumption-type VAT is a tax imposed on TG or TS consumption, including general capital goods and will become an Input Tax, which can be credited with an Output Tax. Thus, capital goods will only be subject to the VAT once. Due to this, there will be no double taxation of capital goods because of the tax crediting mechanism [30].

Blockchain technology can provide easy access for each node to check the e-Invoices issued by a transaction counterparty. In a conventional system, the buyer TE must validate the e-Invoice issued by the seller's TE; however, in a blockchain technology-based system, this is no longer needed. On the other hand, the DGT must also validate the e-Invoice issued by the TE seller. This is because the e-Invoice issued by the seller's TE is connected to the TISN in the blockchain technology-based system using a hashing function. The hashing function makes it impossible to use unrecorded tax invoice data to issue a fictitious e-Invoice that does not match the actual transactions.

In addition, blockchain technology can also solve problems that often arise in e-Invoice (digital tax invoices) and e-Nofa (a website to apply online for a Tax Invoice Serial Number). Before issuing an e-Invoice, a TE must request a TISN by applying directly to the tax office where the TE is confirmed. TISN is data in the VAT system that is not confidential and does not cause problems if known by others. The enormous number of TE accessing the Directorate General of Taxation's (DGT) server simultaneously causes frequent errors. These applications often cause TE to experience difficulties in carrying out their tax obligations. 
There are several previous studies related to the use of blockchain technology. First, Myung San Jun's research [34], entitled Blockchain Government-A Next Form of Infrastructure for The Twenty-First Century (Journal of Open Innovation: Technology, Market, and Complexity, 2018), aimed to determine why blockchain is currently widely used by the government systems in several countries. Jun's research showed that many countries are adapting blockchain in their government because, unlike other technologies, it is directly related to community organizations. The characteristics of blockchain make it possible to implement social technology that can replace existing social apparatus, including government bureaucracy. There are three similarities between blockchain and bureaucracy. First, both are determined by a regulation and are carried out based on predetermined rules. Second, they both work as information processing machines for society. Third, both work as tools that are trusted by the community. Thus, it can be stated that blockchain technology could be an excellent tool for social innovation not only for increasing government effectiveness, but also for improving society.

Ayubjon Solehzoda's research [16], entitled Information Technologies in the Tax Administration System of VAT (Journal of Advanced Research in Law and Economics-2017), used a qualitative approach that aims to explain the benefits of using information technology in tax administration, particularly in a VAT system. Solehzoda's research identified four alternatives that could be considered by governments when utilizing electronic technology to develop a VAT system, namely developing regulations and legal products, creating databases and developing infrastructure as the main support in implementing electronic information and technology in the tax system, developing technical equipment and software used in creating databases, and efforts to develop the ability of the tax authorities to serve taxpayers in carrying out their tax obligations.

In addition, there is a research paper by Alkhodre, et al. [15], entitled A Blockchain-Based Value Added Tax (VAT) System: Saudi Arabia as a Use-Case (International Journal of Advanced Computer Science and Applications-2019), which aims to present ideas and solutions for using blockchain technology in the design of a VAT collection system in Saudi Arabia. The results of Alkhodre's research state that the current era of computerization shaped the tax collection system into an unusual form and changed the relationship between citizens and tax authorities. Digitalization in the VAT system has become a concern for several countries as new regulations emerged such as the Standard Audit Files for Tax (SAF-T) in Europe or real time invoicing mechanisms in South America and Brazil. In terms of blockchain technology, there are two reasons why this technology can be implemented in the VAT system in Saudi Arabia. First, blockchain provides a reliable ledger that cannot be manipulated by any party because every transaction in the system will always be known by the smart contract. Second, blockchain provides transparent record keeping.

The last one, Saragih and Setyowati's research [35] aimed to determine the benefits of blockchain in modernizing tax administration, the factors affecting blockchain technology in modernizing tax administration, and the readiness of the government and related parties to use this technology in modernizing tax administration in Indonesia. The results of this study showed that the use of blockchain technology in the modernization of tax administration in Indonesia has several benefits, namely it increases transparency, speeds up transactions through disintermediation, and is immutable and accurate. The use of blockchain technology is influenced by infrastructure, capability, and government policy factors. There is no government policy that regulates the readiness to implement blockchain technology in Indonesia. The infrastructure that supports the application of blockchain technology such as internet networks, server computers, and digital identities, has not been fulfilled. In addition, blockchain technology in Indonesia is not yet fully developed and blockchain literacy is still low.

\section{Research Method}

We used a qualitative research approach because we aimed to provide a thorough picture of a social phenomenon. The social phenomenon discussed in this study is the era of the industrial revolution 4.0 and the application of blockchain technology in the VAT system in Indonesia. This type 
of purpose-based research is descriptive because its purpose is to analyze blockchain technology models that can be applied in the VAT system in Indonesia. This type of research based on benefits aims at developing the reader's knowledge of the application of blockchain technology in the VAT system in Indonesia. Blockchain technology is a new technology that is not yet known by many people because it has not been massively implemented in Indonesia. Therefore, this research will increase the readers' knowledge regarding the role of blockchain technology in a VAT system.

Data collection techniques used were field studies through conducting in-depth interviews of previously established speakers and literature studies by studying literary sources related to the research topics. In-depth interviews were conducted to gather supporting data through immersive and thorough discussions on this research topic with relevant parties. The interviewees were experts in their fields that were relevant to this research. The selection of respondents was based on their experience and competency in blockchain technology. We intended for the respondents to provide a detailed and in-depth explanation of the topics and problems discussed in this study. Therefore the respondents had to be carefully selected based on their understanding of the research problems and the actual conditions regarding the application of blockchain technology in a VAT system. The information obtained in the in-depth interviews was considered as primary data, which were processed to answer the research questions.

The informants in this study were from 4 groups, namely government agencies, academics, practitioners, and members of associations. Firstly, the informants from the government came from 5 agencies, namely the Directorate of Information and Communication Technology DGT, Directorate of Taxation Regulation I DGT, Fiscal Policy Agency, Directorate General of Informatics Application of the Ministry of Communication and Informatics Indonesia, and Center for Financial Information Systems and Technology Ministry of Finance Indonesia.

In-depth interviews were conducted with staff of the Directorate of Information and Communication Technology, DGT to gain a broader view of the extent to which technology is applied in the VAT system and how to design suitable blockchain technology for the VAT system. DGT has the role of regulator and implementer of the existing taxation policies in Indonesia. This indicates that the DGT is directly involved in the Indonesian taxation system. Interviews were conducted with the Directorate of Taxation Regulations I DGT with the hope of gaining more insight and creating a broader view of the best design for implementing blockchain technology in the VAT system.

The Fiscal Policy Agency is an organization that plays an important role in formulating policies, plans, programs, and recommendations related to fiscal policies in accordance with applicable laws. In-depth interviews conducted with the Fiscal Policy Agency were expected to provide broader views and information regarding policy formulation related to the application of blockchain technology in the VAT system. In-depth interviews conducted with the Directorate General of Information Applications of the Ministry of Communication and Information were expected to provide information and a broader view of network infrastructure that can support the application of blockchain technology in the VAT system. In-depth interviews conducted with the Center for Financial Information Systems and Technology Ministry of Finance Indonesia were expected to provide information and a broader view of how government plans and policies are related to the application and development of technology in the VAT system.

Secondly, the informants representing the academics were lecturers of the Faculty of Administrative Sciences and the Faculty of Computer Science, Universitas Indonesia. As academics, lecturers have excellent knowledge and a theoretical understanding of the field. In this study, interviews were conducted with lecturers of taxation, especially VAT, who had a broad understanding of the application of technology in taxation.

Thirdly, informants in this research came from the field of taxation and blockchain technology. As experienced parties with direct involvement in the field, the practitioners were judged to be able to provide a deeper understanding of the practice in the field on how blockchain technology could be applied in the Indonesian VAT system. The practitioners specified in this study included those working 
for Achilles Advanced Systems Ltd. (OnlinePajak); CITA (Center for Indonesia Taxation Analysis); RSM Indonesia, one of the leading tax consulting offices in Indonesia; Blocktogo, an IT development company in Indonesia; and Tokocrypto, a cryptocurrency exchange company in Indonesia.

Interviews conducted with OnlinePajak were expected to result in deeper knowledge about what kind of application of blockchain technology is being applied at OnlinePajak from the start of planning to date and were expected to provide their views on how to properly design blockchain technology and the factors that support and hinder its application in the VAT system. CITA is an organization that actively conducts research related to the latest issues in taxation. In addition, CITA also provided views on the implications of blockchain technology for the taxation system.

RSM Indonesia is one of the leading tax consulting firms in Indonesia. In-depth interviews with RSM Indonesia as a consultant in the practice of taxation were expected to add deeper insights into how the VAT system is performing in the field and also the potential for developing blockchain technology in the VAT system. In-depth interviews conducted with Blocktogo and Tokocrypto were expected to add deeper insight into blockchain technology and provide an overview of the design of an appropriate implementation model in the VAT system.

The last informants, from associations and organizations, were from the Indonesian Blockchain Association and the Indonesian Blockchain Network. As a new technology that is still developing, blockchain is still relatively unknown in Indonesia. Therefore, the existence and role of associations and organizations that specifically delve into blockchain technology in Indonesia will be of great benefit to many parties. In-depth interviews conducted with the Indonesian Blockchain Association and the Indonesian Blockchain Network were expected to provide a detailed explanation of blockchain technology and special views on the implications and application of blockchain technology in the VAT system.

Semi-structured interviews were conducted using a list of questions prepared in advance and followed the dynamics of the discussions with informants and the information gained. The interview questions included: (a) views on the application of tax technology in the VAT system in Indonesia (especially the e-Invoice system); (b) views on technology development to overcome problems in the VAT system (especially the e-Invoice system); (c) understanding of blockchain technology and its development in Indonesia; (d) an overview of the application of blockchain technology in the e-invoicing system; (e) significant factors taken into consideration in applying blockchain technology to the VAT system; (f) designing the appropriate blockchain technology (concepts, types, mechanisms, participants, etc.) implementation model for the VAT system; and (g) matters to be considered by the government in formulating policies related to the application of blockchain technology in the VAT system.

It was very important to determine the research site because it had to be directly related to the research topic. This research site was located in the DKI Jakarta area, which comprises several agencies and practitioners, namely DGT, Fiscal Policy Agency, Ministry of Communication and Information Indonesia, Center for Financial Information Systems and Technology Ministry of Finance Indonesia, OnlinePajak, CITA, RSM Indonesia, Blocktogo, Tokocrypto, Indonesian Blockchain Association, and Indonesian Blockchain Network. In addition, the academic environment was also within the research site, namely Universitas Indonesia.

The study was conducted at one point in time and was not conducted at different times to make comparisons with previous research possible. The primary data collection was conducted over a period of approximately 5 months, from August to December 2019. The data analysis technique used was a qualitative data analysis technique. This research began by studying the data of interviews with informants, notes made during field studies, and a literature study of data in the form of documents related to blockchain technology and VAT systems in Indonesia. This was followed by a reduction and selection of data that was more focused and relevant to the research issue. This was followed by further in-depth analysis of the data. 
Research analysis was performed by linking selected data to the research problems. The data were then presented in the form of descriptions, tables, and graphs based on the results of interviews and literature studies. The data were presented to support the analysis conducted in this study. Finally, the results of the study were concluded based on the data and analysis presented.

This research is not without limitations as it only discusses the application of blockchain technology in the VAT system in Indonesia. Blockchain technology is a transparent technology in which each party belonging to the blockchain chain will know the data or information that are in the blockchain. Therefore, blockchain technology can be used for transparent data only. In VAT, there are data that is transparent and secure for others to know, namely the Tax ID Number and the TISN. The topic of this research is limited to the scope of VAT because VAT is one of the types of taxes that is considered appropriate for the application of blockchain technology.

\section{Results}

After completing the analysis, as shown in Figure 1, blockchain technology can be applied in the TISN systems using the permissioned private blockchain type. This type of blockchain technology allows the DGT to run a private but still customizable blockchain system so that it can determine which parties are nodes and the extent of the authority those parties have in the blockchain technology network.

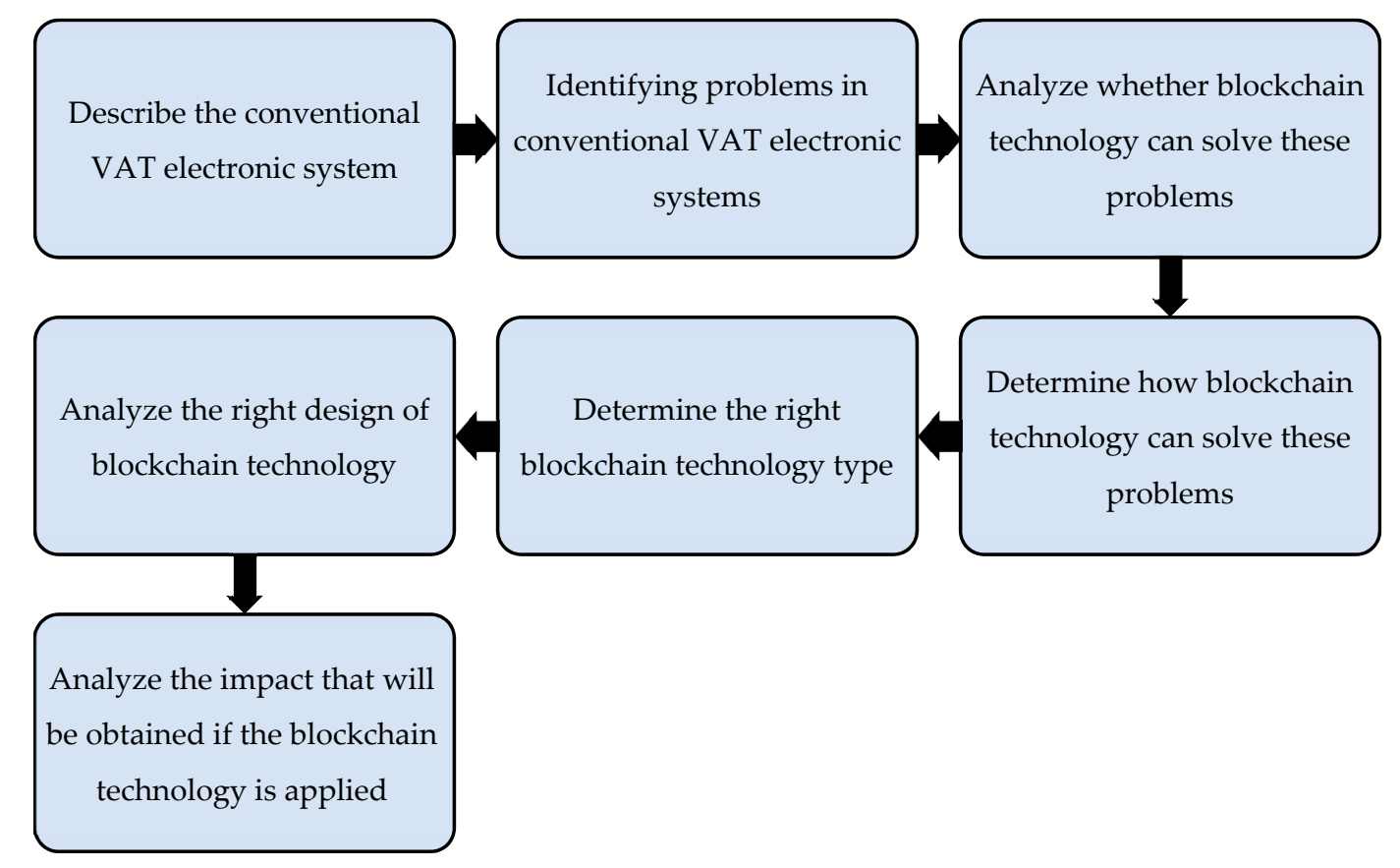

Figure 1. Scheme of the research analysis stages.

Before applying blockchain technology in the VAT system in Indonesia, it is necessary to design the desired implementation model in accordance with the DGT standards. The DGT should deepen its knowledge on how blockchain technology can be utilized by VAT systems in Indonesia. This is because, in principle, blockchain technology consists of various types of blockchains and implementation models that can be tailored to the needs and benefits to be achieved. Figure 1 shows the steps performed by the researcher to perform the analysis.

As an initial step, a description is presented of how conventional VAT electronic systems are applied currently. A simple illustration, as in Figure 2, is provided to make it easy to understand the process: 


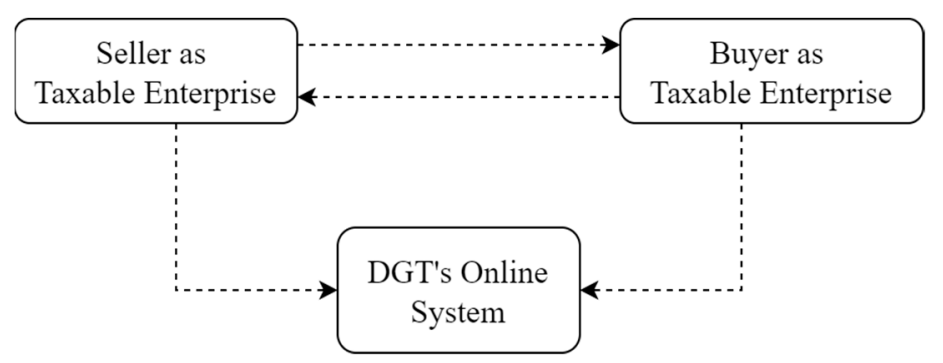

Figure 2. Buyer and seller position scheme in the Indonesian VAT system.

When the seller (a party that is classified as a TE), conducts a transaction to submit the taxable goods or taxable services to a buyer that is also classified as a TE, there is an obligation that must be done, which is to collect VAT from the buyer, as in Figure 2. VAT rates are charged in accordance with the provisions applicable in Law No. 42 of 2009 on VAT. Resmi [31] explained that there is a method of calculating VAT by deducting the Output Tax from the input tax. This deduction method is called the credit method or input tax crediting method.

At the time of the submission of taxable goods or taxable services subject to VAT, there is proof of a tax collector payable called a tax invoice. The seller is required to create an Output Tax invoice for the submission of taxable goods or taxable services while the buyer will receive the tax invoice as an Input Tax invoice for the purchase of taxable goods or services. Both the seller and the new buyer can perform the mechanism of crediting the Output Tax and Input Tax if the tax invoice has been issued.

Before issuing a tax invoice as proof of a tax deduction to make an Input Tax credit, a TE must submit a request for a TISN to the DGT. The application can be made online or through a tax office where the TE is confirmed. If the TE wants to create the TISN online, then the TE can make a request through the e-Nofa application. After the TE has submitted the TISN request through an e-Nofa application, the process of issuing the TISN to the TE will be carried out. For the TISN to be issued by the DGT, several requirements must be met, i.e., the entity has been confirmed as a TE and is in possession of an electronic certificate, as well as an activation code, and a password.

After the TE has submitted a TISN request and fulfilled the specified requirements, it is only then that the TISN will be provided by the DGT to the TE. The TISN model of the TE is an allotment system. A TE that followed the e-Invoice scheme will periodically be allocated a TISN through the e-Nofa application by the DGT. After the TE obtains a TISN, they can issue tax invoices for transactions made with opposing transactions. If the e-Invoice has been issued, then the next obligation for the seller is to deposit and report the taxes collected to the DGT.

On the other hand, the buyer must check the e-Invoice obtained from the seller. The buyer must check whether the tax invoice has been properly issued by the seller through the e-Invoice application based on the QR code displayed in the e-Invoice. After that, the buyer can credit the Input Tax to its output tax. If the result shows that it is underpaid, then the buyer must deposit the tax to the temporary state coffers. If the result shows that it is overpaid, then the buyer can file a refund or restitution to the state. At the same time, the DGT online system performs transaction monitoring, validates invoice recipients, and invoice issuers are officially registered in the DGT system. This process is simple on the existing VAT electronic system.

The second stage is to identify problems in the conventional electronic VAT system. Before applying blockchain technology in the VAT system, the DGT must first identify the problems generated by the existing system. When the problems have been identified then the extent to which blockchain technology can solve the problem should be mapped. Following are the problems that often arise in conventional VAT electronic systems and whether they can be addressed by blockchain technology:

a. The lack of optimal e-Nofa application performance

DGT servers are simultaneously and directly accessed by hundreds of thousands of TE to make TISN requests. This overload of requests often leads to a reduced performance of e-Nofa applications 
and causes the system to hang. There were also problems related to the DGT servers, which were also often interrupted when accessed simultaneously by multiple parties. This causes taxpayers to experience difficulties when performing their tax obligations.

\section{b. Excessive stages to complete}

Based on the explanation described above, the current conventional VAT system is a very long process. The buyer must validate the input and output tax, the seller must also request a TISN, and the DGT system validates the tax and transaction. As a result, both the TE and the DGT must go through many stages.

\section{c. Fictitious tax invoices}

The inefficiencies of the VAT system triggered another problem, namely the emergence of tax fraud practices that produce fictitious tax invoices. A fictitious tax invoice is an invalid tax invoice issued by a taxpayer not confirmed to be a TE or for transactions that did not actually occur. This fraud is conducted to enlarge taxpayer tax credits, and thus the VAT deposited will be smaller than what it should be. This is greatly detrimental for the state.

\section{Discussion: Blockchain, Value Added Tax, and Open Technology}

An analysis was performed to determine whether blockchain technology will be able to help solve these problems. Before performing the analysis, it was necessary to know when the DGT should create a system based on blockchain technology, online or offline. This is because the DGT cannot implement this new blockchain technology in the VAT system indiscriminately. The DGT must carry out benefit mapping first so that when this technology is implemented in the future, it will be able to solve existing problems and provide effective and efficient results.

\subsection{Blockchain Application as an Open Technology Innovation in e-Invoice VAT System}

As a technology that is developing and attracting the attention of many, blockchain technology will pose challenges in the future. Thus, organizations must constantly come up with innovative ideas to face them [36]. With the potentials and opportunities offered by blockchain technology, the application of technological innovation in an organization should be carried out by all parties involved. Blockchain is considered as a revolutionary technology [37] and one of the best innovations after the internet [38]. This is because of its many benefits, such as speeding up transaction completion, reducing the risk of fraud, increasing transaction auditability, and increasing the effectiveness of supervision [39].

Blockchain technology (distributed ledger) is a very real form of open technology innovation. Once information has been recorded in the blockchain database, it is very difficult to delete or change the data [23]. This technology uses multiple participants in the network to reach consensus and distributes transaction records digitally to all the networks involved in real time. This enables collaboration between business entities and individuals as well as transparency of business processes and data [40]. In general, the use of blockchain technology allows the real time disclosure of financial statement information that can be accessed by both internal and external users [39]. This technology leads to changes in interaction models and increases the system transparency and efficiency [37]. It is not surprising that blockchain technology is considered a very useful form of open innovation and is widely used in various sectors, such as the government [11] and business sectors [12]. Additionally, blockchain technology can also be implemented for effective and efficient tax administration-for example, in the context of the VAT system.

Blockchain technology in the VAT system has the potential to strengthen the system and give more trust to the parties in the network, including the government and TE. With a system that provides data openness, blockchain technology is an open technology innovation in the VAT system and particularly 
in e-invoicing, because it can increase the system transparency and efficiency. In addition, the use of blockchain technology to store and distribute data can be effectively utilized to carry out risk assessment in systems [37]. Thus, due to its characteristics, i.e., transparency and distributed data, blockchain technology can be said to be open technology innovation in the VAT system.

Considering that the main characteristics of blockchain technology are transparent and distributable data, this means that each party acting as a node in the blockchain technology network will receive the same distribution of data or information. Thus, this technology can only be utilized for transparent data, whereas almost all data related to taxpayers are confidential and not transparent. Data that are not considered to be crucial and secure when viewed by other parties includes the TISN. Therefore, in principle, blockchain technology can be applied in TISN delivery and the tracking systems from the DGT to TE.

Regarding the TISN rationing system from the DGT to the TE, the following is a simple scheme that illustrates the difference between the conventional TISN granting system that is currently in effect and a system using blockchain technology:

In the conventional model, as shown in Figure 3, the DGT online server is accessed by all TE periodically and simultaneously. This system shows that the position between the DGT server and the TE becomes misaligned due to the existence of the server (the DGT becomes a client or TE). This misalignment often causes DGT servers to experience downs or errors when accessed simultaneously by multiple parties. However, when compared to blockchain-based systems where there is no server and client system, both the DGT and TE have the same position.
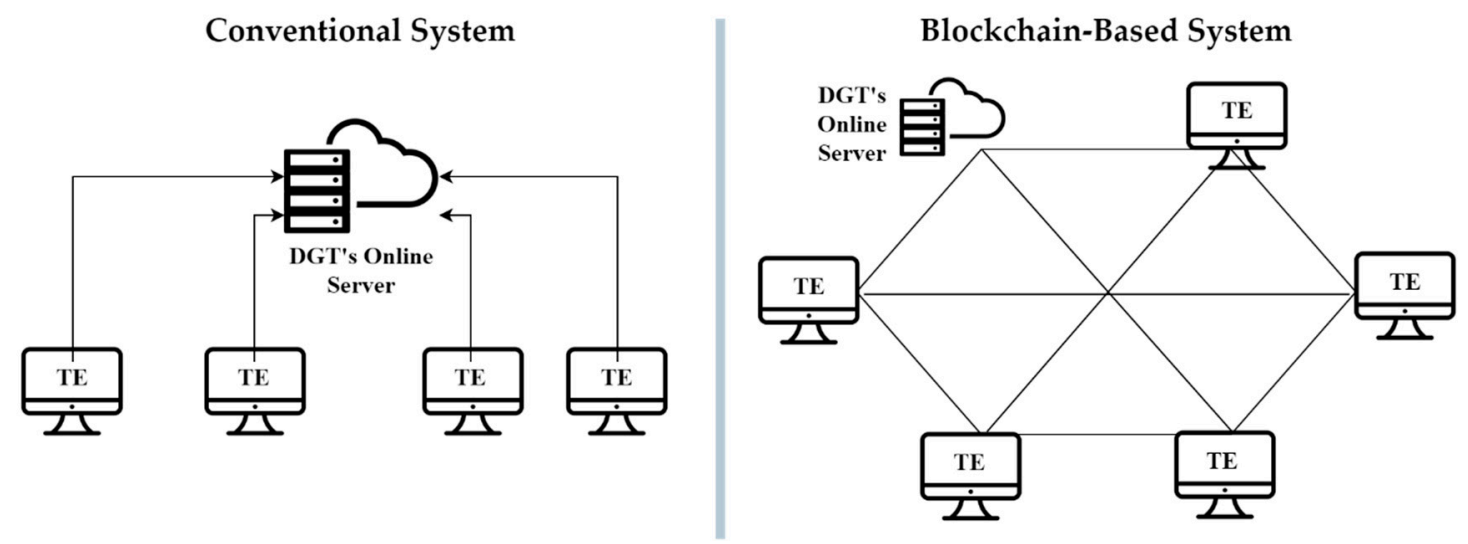

Figure 3. Comparison of conventional and blockchain-based Value Added Tax (VAT) systems.

The equality of these positions occurs because of the decentralization in blockchain technology. Decentralization causes each party in the blockchain technology network to have an equal position and no party has the role of master (DGT), as in Figure 3. Thus, blockchain technology has the potential to be implemented in the TISN delivery system from the DGT to TE. The implementation of blockchain technology in the TISN system speeds up performance and the TE goes through fewer stages because of the automation system. This is in line with a statement made by a resource person, a blockchain practitioner in Indonesia, who said,

"Oh, of course, automation is for all kinds of things, for example, I am tired of income tax, and VAT, it is the same thing; this blockchain is for automation and monitoring so there is no such thing as a tax that is not connected to the government and so it becomes more optimal." (In-depth interview with an informant at Blocktogo, 29 November 2019).

As the DGT and TE have the same position, all TE do not have to access the same server anymore but are able to access TISN on their own using the VAT electronic system, which is based on blockchain technology provided by the DGT. Thus, it is expected that the problems encountered in the conventional VAT electronic system, when TE simultaneously access the DGT server, could be resolved. In addition, 
the move will turn the system into a flow of data instead of a flow of goods so that supervision will also be easier. The following is a statement from an academic resource person regarding how the flow of data can facilitate VAT supervision:

"This manual still uses the traditional system. Generally, they are - in the traditional system, it is a flow of goods, now this must be replaced with a flow of data. So, the data is - if the flow of data is all reliable, the supervision is easy, and we have to look at it again later, perhaps if the supervision must be based on some data." (In-depth interview with a professor and lecturer at Faculty of Administrative Sciences, Universitas Indonesia, 19 November 2019).

In addition, the implementation of blockchain technology in the VAT system may also have implications for improving the user experience of taxpayers. User experience is an important thing that must be considered in the application of a technology. This is in accordance with the statement from the following academic resource person:

"Online DGT will be able to cooperate with third parties who can provide added value to the community with their respective technologies. Finally, the third-party tax server can get 10 Rupiah for every transaction, no problem, and from Online DGT there will be no need to experience that anymore when the server is down, etc. Things like that won't exist anymore, that's what I mean with user experience. When user experience is considered, it will have an impact on infrastructure and people." (In-depth interview with a lecturer at the Faculty of Computer Science, Universitas Indonesia, 20 November 2019).

With the implementation of blockchain technology in the VAT system, taxpayers as users will feel comfortable because they can avoid problems, such as system hangs or bugs. Blockchain technology can provide easy access for each node to check e-Invoices issued by transaction counterparties. In the conventional system, the buyer TE must validate the e-Invoice issued by the seller's TE, but in a blockchain technology-based system this is no longer needed. On the other hand, the DGT must also validate the e-Invoice issued by the seller TE. This is because the e-Invoice issued by the seller TE is connected to the TISN in the blockchain technology-based system using a hashing function. The hashing function makes it impossible for unrecorded tax invoice data to be used to issue a fictitious e-Invoice that does not match an actual transaction. This a statement corresponds to the following statement made by a resource person from the Head of Support System Development Section I of the Directorate of Information and Communication Technology DGT:

"Yes, I see the advantages described earlier, first is security and the ease of checking on the transaction counterparty. How is this possible? The data is in the node, so the advantage of the blockchain is that the data is with us. I have Data A, my data is in A. That's right, isn't it? So, we don't have to always contact our superiors online because the data is there." (In-depth interview with an informant at the Support System Development Section I of the Directorate of Information and Communication Technology, DGT, 4 December 2019).

The following is an analysis of the types and designs of blockchain technology implementation models that can be applied to the VAT system in Indonesia, in particular, the TISN granting system. Blockchain consist of three types, namely public, consortium, and private [26]. In order to determine the type of blockchain technology that can be applied in the TISN delivery systems, first, the characteristics of the agencies planning to implement it should be known. As a government agency, the appropriate type to apply within the scope of DGT is the private blockchain. This is because the security of taxpayer data is crucial. The security of the data makes it impossible for DGT to implement a public blockchain type because it is too risky for the dissemination of taxpayer personal data.

Since data security is the main issue to take into consideration, the type of blockchain technology that is deemed to be suitable is the private blockchain. The private blockchain is the right type because in data security, the nature of taxpayer data is very confidential, and it will be dangerous if accessed by 
other parties. This is supported by the following statements made by the Chief Operating Officer of Tokocrypto as a blockchain practitioner in Indonesia:

"In my opinion, this concept must make use of the private blockchain. Why? The credentials can only be obtained by a few log-in accesses, then the node that performs the validation is also selected, for example the issuer of the number or there are several other parties." (In-depth interview with an informant at Tokocrypto, 10 December 2019).

As secure data, TISN is transparent because it is not confidential. If a TE knows the TISN of another TE, it will not be a problem and will instead provide data transparency. In addition, the data displayed in the block scattered across the nodes of interest do not contain all transaction data but only the headers of those transactions. This is because the size of the data contained in a block cannot be large given that not all TEs as nodes have significant storage capacity.

Regarding granting permission to nodes, permissions in blockchain technology consist of permission-less and node permissioned. The following statement regarding granting access permits to nodes was made by a resource person, Chairman of the Indonesian Blockchain Association:

"I think it's better to use a permissioned private blockchain so that there will be public involvement, but it will still be possible to choose who can be the nodes." (Interview with an informant at the Indonesian Blockchain Association, 6 December 2019).

The permission-less blockchain allows all new users to participate, validate, transmit, or forward transactions, as well as add or have blocks in the blockchain technology network. A permissioned blockchain only allows registered nodes to validate in the blockchain technology network [7]. A permissioned blockchain is more suitable for industries that are regulated [41]. Therefore, the right type of permission to be applied in the TISN system based on blockchain technology is the permissioned private blockchain.

Permissioned private blockchain allows the DGT to run a private but still customizable blockchain system where the DGT can determine which parties are nodes and the extent of the authority of those parties in the blockchain technology network. This can then be set out in a smart contract. A smart contract is a series of agreements that serve as a business transaction regulator. A smart contract is stored and executed automatically in the blockchain as part of a transaction. Smart contracts can be trusted because of their characteristics i.e., they are immutable and distributable. Immutable means it cannot be changed, while distributable means the contents of the contract will be distributed to all parties in the blockchain network so that it can be validated directly. The following is a statement regarding smart contracts made by a resource person from the Head of Support System Development Section I of the Directorate of Information and Communication Technology DGT:

"This smart contract is the real power of the blockchain. So, we can just place smart contracts between TEs; the DGT doesn't have to get involved. The DGT participates in the sense that it is the one who makes such numbers, in the sense that for example there are TE $A, T E B, T E C$, and TE D. TE A has taken the number 1-1000; this is the smart contract that regulates it. So, the smart contract between individuals is that TE A has taken the number 1-1000. TE B means 1001-2000, now it works for the invoice number." (In-depth interview with an informant at the Support System Development Section I of the Directorate of Information and Communication Technology, DGT, 4 December 2019).

Smart contracts can be likened to rules of a game that require the parties involved to agree and obey the rules therein. The following is a statement from the Chief Operating Officer of Tokocrypto as a blockchain practitioner resource person about how smart contracts can provide security for the parties involved in it:

"When there is a change in a smart contract, the entire ecosystem of the connected platform must know about it. So, it can't be unilateral, that's the difference. Smart contracts aim to make everyone agree 
with the rules of the game. So smart contracts are like the rules of the game, why agree because smart contracts aren't that easy to change." (In-depth interview with an informant at Tokocrypto, 10 December 2019).

Smart contracts can determine what data each node can see, regulate TISN granting to TE, and who is a node in the blockchain technology network. When it comes to data, it is not possible to place all invoice data in all nodes because first, they have to provide space/storage sufficient for DGT central data (approximately $10 \mathrm{~TB}$ ) and secondly, taxation data are highly confidential and should not be viewed by unauthorized parties.

The importance of maintaining the confidentiality of tax data is set out in Article 34 of Law No. 28 of 2007 on General Provisions and Procedures for Taxation. The provisions described in the Act show that the security of taxpayer data is crucial and should be considered seriously. Thus, what data may exist and what should not exist in the blockchain network should be considered. TISN data are not considered very confidential and are light enough to be distributed. This can help the DGT system to become faster. In addition, the data in the blockchain network should also be useful for other nodes.

If all TE are in the blockchain network at the same time as the DGT, TE should not be able to see the data of other TE transactions that have no connection with them. For example, when TE A conducts transactions with TE B, only TE A and B need this data; not TE C, TE D, or any other TE. Thus, the smart contract should be regulated regarding who has access to the transaction data, namely the seller, buyer, and DGT only.

The function of layering for multi signatures in smart contracts makes it possible to set up which enterprise is authorized to see transaction data in the blockchain network. In that way, through smart contracts, leveling any parties with higher or lower authority is possible. In addition, it can be determined that DGT reserves the right to have all taxpayer data on the DGT node, but on each TE node there are only data related to the TE and its transaction counterparty's node.

As previously explained, in order to consider the amount of data contained in the blockchain, the data that are blocked are not all transaction data between TE but only headers from the transaction data. In addition, the data size should also not exceed the capacity of each node. The size of the data in the blockchain should be considered because not all TE that act as nodes have the same data storage capacity. This is very important because with the distribution of all data to nodes in the blockchain technology network, all nodes must have adequate storage capacity. This is one of the shortcomings of the blockchain technology. If a node does not have sufficient data storage capacity, then the person who owns the node cannot participate in the blockchain technology network.

What data are to be known by fellow TE versus transactions can be set in the smart contracts. We recommend that the data displayed, such as the TISN, transaction headers, and timestamp header, not be confidential data. When the taxable good or taxable service has been handed over or resold to another party, there will be a new block containing similar data related to the sale to the other buyer, which is classified as a TE. With this blockchain-based TISN system, the DGT can trace where the taxable goods came from and who sold them first. In that way, the process of transparency of transactions or supply chains of taxable goods or services will be highly visible and supervision will be easier to achieve.

The final aspect concerns the parties involved. As previously explained in the TISN delivery systems based on blockchain technology, the parties involved are the DGT and the TE. However, the DGT still requires external partners to implement blockchain technology in the VAT system. Before this system can be applied to taxpayers, the DGT must register it with the Ministry of Information. The DGT may also ask the National Cyber and Crypto Agency (NCCA) to provide assistance related to data security standardization in the blockchain technology network of the VAT system. The Application Service Provider (ASP) from the DGT can also act as a supporter to implement blockchain technology in the VAT system in the future. Based on the description above, the following is a simple illustration of the mechanism of the e-Nofa system based on blockchain technology. 
The illustration above, as in Figure 4, shows that by using blockchain technology, there will be maximum transparency and data security. The data recorded in each block of each TE involved in a sale or purchase transaction of taxable goods or taxable services with its transaction counterparty will be locked with the hashing function of the blockchain technology. With this function, a TE cannot cheat by manipulating data in a block that has been recorded in the blockchain technology network. The chain system owned by the blockchain technology also enables the DGT as a regulator to conduct comprehensive monitoring and track transactions. Thus, all data recording of transactions that produce VAT will be tracked and recorded properly and securely.

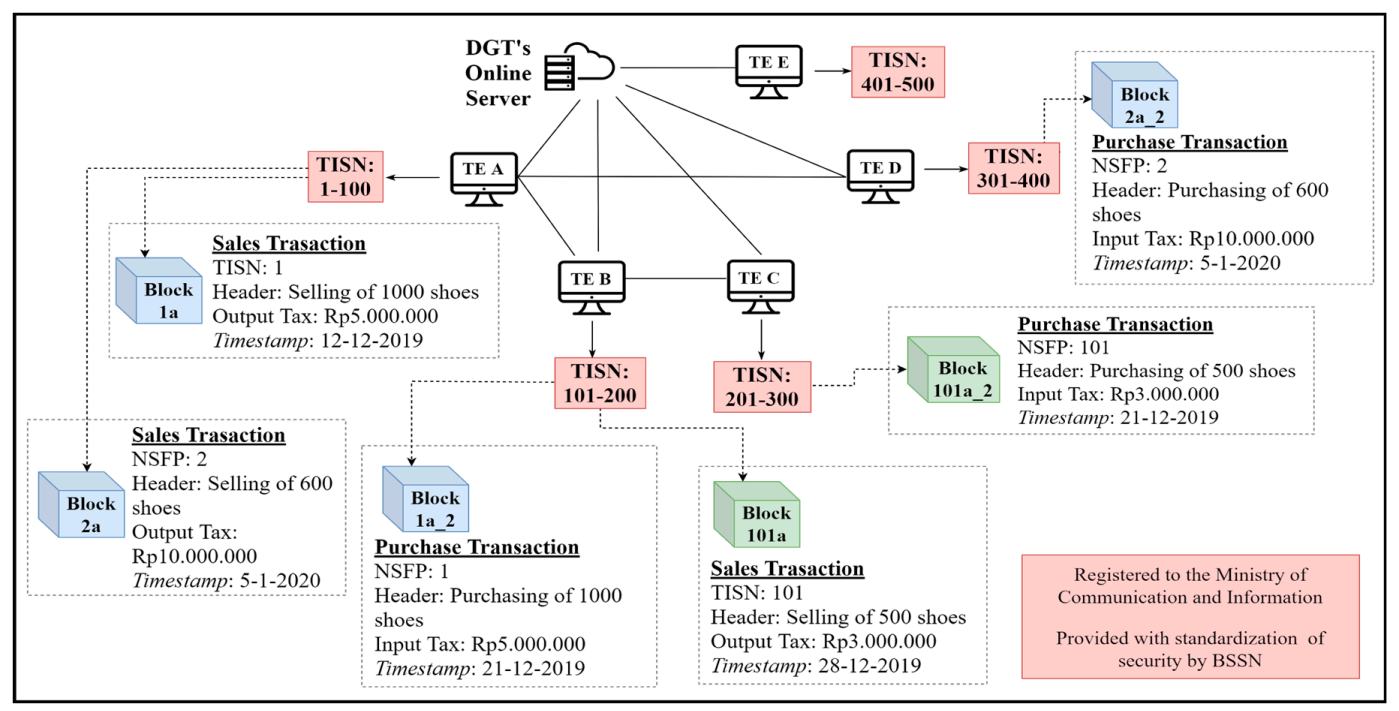

Figure 4. Illustration of a blockchain-based Tax Invoice Serial Number (TISN) System.

In addition, the top TISN that is left at the end of the tax period and has not been used by TE will directly be seen by the DGT through the blockchain technology system, as shown in Figure 4 . In that way, oversight of the remaining TISN will be easier to conduct because it is very transparent. Therefore, with careful planning and mapping, blockchain technology will significantly enhance the efficiency of the VAT technology system in Indonesia. However, the DGT also needs to mitigate the risks and flaws that blockchain technology could pose. The aim is to allow the application of blockchain technology in the VAT system to run efficiently in accordance with the DGT's objectives. When the transparency of taxation has improved, this will affect the taxpayers' compliance in carrying out their tax obligations. Thus, everything concerned with VAT will become clear and auditable.

\subsection{Views of the Government, Academics, Practitioners, and Associations Regarding to the Application of Blockchain Technology in the VAT System Particularly for the e-Invoice}

\subsubsection{The Government}

Before applying blockchain technology in the VAT system, especially for e-invoicing, the DGT must refer to the existing regulations first. Regulations are important matters that must be taken into consideration. However, existing regulations should not limit the space for DGT to develop blockchain technology. It would be beneficial if tax regulations in Indonesia were made to be more dynamic and easily adaptable to existing developments. Regarding regulations, there must also be strong support from parties with higher authority in the government or policy makers. If the Directorate of Information and Communication Technology (ICT) of the DGT has initiatives related to technology development, the Directorate of ICT of the DGT must first refer to the taxation regulations whose scope is within the Directorate of Taxation Regulations I or II.

Apart from that, there is another directorate, namely the Directorate of Business Processes (TPB) that acts as the bridging party if the regulation relates to IT or anything that is implemented in nature. 
The ICT Directorate of the DGT can then begin to play its role related to technology development even though it cannot directly create applications or coding. The ICT Directorate cannot directly implement new technological innovations but must first go through decisions and considerations from several other directorates, such as the Directorate of PP I or II and the Directorate of TPB.

This bureaucratic process requires the approval and support from the top management of each directorate. In this regard, the researchers in [35] stated that the main decision maker in the company (the top management) has an important role in deciding whether an organization can implement blockchain technology or not. The following is a statement from a resource person from the Head of Trade and Industry Value Added Tax Sub-Division Fiscal Policy Agency regarding the importance of top management support in the application of blockchain technology:

"Top management support is very important because without it, it will not work. Currently our leadership is very supportive of the system to increase the efficiency of tax administration. Because when it is efficient, it will be effective, and then the revenue will increase." (In-depth interview with an informant at the Trade and Industry Value Added Tax Sub-Division, Fiscal Policy Agency, 27 November 2019).

This statement indicates that support from top management plays an important role in the implementation of blockchain technology in the Indonesian VAT system. On the other hand, the government should also consider how prepared and ready the organization is to apply this technology. The DGT is an agency that supports its employees to continue to improve their knowledge and skills by instilling a long-term learning culture and norms for senior officials as well as employees. This learning culture will support the development of employee knowledge and skills related to blockchain technology.

The DGT as the tax regulator and implementer in Indonesia must understand how the application of blockchain technology is not something that is general but must start from a basic level. This is because an incomplete understanding of the technology can lead to misconceptions regarding the benefits and applications of blockchain technology. Readiness does not only concern human resources but also refers to the business model. Regarding the application of blockchain technology in the e-invoicing system and its relationship with the existing DGT business model, the following is a statement from the Director General of Directorate General Informatics Applications Ministry of Communication and Information Indonesia:

"Yes, the business model is highly adaptable because the model is already electronic. If it were still on paper, it would be difficult; but VAT is already electronic using e-Invoice, so there is only one step left. But in fact, taxpayers are already used to filling out e-Invoices, so the implementation of this blockchain does not change the business processes that are currently being carried out by the DGT and taxpayers." (In-depth interview with an informant at the Directorate General Informatics Applications, Ministry of Communication and Information Indonesia, 10 December 2019).

The above statement explains that because the tax invoicing system is now electronically based, it will not be difficult to adjust to the existing DGT business model. Thus, the current e-invoicing business model supports the implementation of blockchain technology in the e-invoicing system. The government must also pay attention to the readiness of technology infrastructure to implement blockchain technology. The following is a statement from the Head of Support System Development Section I of the Directorate of Information and Communication Technology DGT regarding this matter:

"After the steps are okay and the innovation can be carried out, we must pay attention to infrastructure. What is the readiness of infrastructure like? The people? A network server should be prepared and so on." (In-depth interview with an informant at the Support System Development Section I of the Directorate of Information and Communication Technology, DGT, 4 December 2019)

Infrastructure is one of the components that must be fulfilled if blockchain technology is to be implemented in Indonesia. Before implementing a technology development initiative, the extent of the 
DGT network and server infrastructure readiness must be checked. It is imperative to develop standard infrastructure components to focus on a higher level in developing value-added services rather than focusing on the core infrastructure. Blockchain technology has the complex and sensitive technical aspects of a decentralized network; therefore, it is important to have a secure and well-developed network infrastructure [42].

The application of blockchain technology in the VAT system, especially for e-invoicing, can be done. However, the government must implement a proper governance framework that includes provisions regarding the responsibilities of each party, rules for approving or rejecting authorized participants, correction mechanisms, applicable laws to handle dispute, and others. On the other hand, before the DGT implements blockchain technology in the VAT system, careful consideration of the security of TE data is required.

Blockchain technology should not be implemented in the VAT system if it will cause TE's personal data and identities to be insecure. Therefore, it is necessary to have a smart contract that regulates this matter. Smart contracts are the strength of blockchain technology that functions as a digital contract that can regulate the existing conditions in the blockchain technology network. The following is a statement from the Head of Support System Development Section I of the Directorate of Information and Communication Technology DGT regarding smart contracts:

"That is, it means this is okay, but you must arrange in a smart contract and that only the sellers, buyers, and the DGT can know that specifically. So, the DGT may have all this data, but the sellers and buyers are only related to the data of the buyer. So, this is possible in the blockchain through this smart contract." (In-depth interview with an informant at the Support System Development Section I of the Directorate of Information and Communication Technology, DGT, 4 December 2019).

With the existence of a smart contract, the DGT can increase the security of TE data in the blockchain technology network. One of the characteristics possessed by blockchain technology is distributable whereby all data will be distributed to all nodes in the network. On this basis, the smart contract can regulate which parties are entitled to know all the details of the taxpayer's transactions. Detailed rules must be made in the smart contract regarding the roles of each seller, buyer, and the DGT. The following is a statement from the Head of Architecture and ICT Capacity Analysis Subdivision of the Center for Information Systems and Financial Technology Ministry of Finance Indonesia regarding the role of smart contracts as a determinant of the parties involved in the blockchain technology network if the DGT is planning to implement it in the VAT system in Indonesia:

"Maybe it can be arranged there. The key is if we want one that is private, the key is that the entities involved are those that have been verified. On a public blockchain, everyone can join, if it's closed, only verified entities are allowed in. So that the process of achieving the forum is easier because the transactions come from and are carried out by trusted people." (In-depth interview with an informant at the Architecture and ICT Capacity Analysis Subdivision of the Center for Information Systems and Financial Technology, Ministry of Finance of Indonesia, 9 December 2019).

It is important to determine which parties will be verified and allowed to see the TE's personal data; in addition, determining the parties involved will simplify the forum agreement process. In this context, the DGT as the tax authority has the right to know all the identities and details of the TE transaction, including the other TE or the credential data of the transaction counterparty. Smart contracts can create and maintain the TE's trust in the security of their data and identity because, as previously explained, this digital contract is very secure and difficult to manipulate.

\subsubsection{Academics}

As a new technology that is still not understood by many parties, the knowledge and skills of government employees and the public on blockchain technology are needed so that its application 
can be utilized optimally. The knowledge and skills regarding blockchain technology must also be mastered so that its use will not create loopholes for taxpayers to commit tax fraud. The following are the views of an academic regarding this matter:

"The problem is the decision to use a certain technology is also important for those who are going to develop it later. What do you want the blockchain to be like, then what is clear, you have to be clear first, about what you want to do, everything? Like e-Invoicing, even though it's already using IT like this and blockchain too, but gaps can still be found in the procedure, that's my opinion. So, before it is implemented, the procedure must first be discussed, the VAT payment mechanism." (In-depth interview with a lecturer at the Faculty of Computer Science, Universitas Indonesia, 11 November 2019).

Mapping the benefits of blockchain technology is very important considering that there are various types and models in this technology that can be adapted to the VAT system in Indonesia. In implementing the blockchain technology in the e-invoicing system, caution should be taken to find loopholes in the system enabling fraud and misuse of data. To deal with the possibility of fraud, academics argued that the type of blockchain technology that should be applied is the private blockchain. Here is a statement of an academic regarding this matter:

"In my opinion, the private blockchain is suitable for the government because they manage the chain. If the public manages it, it can be verified, but the government will have no role to play." (In-depth interview with a lecturer at the Faculty of Computer Science, Universitas Indonesia, 12 November 2019).

If the DGT wants to apply the blockchain technology in the VAT system, partners who are to be invited to work together must be selected based on the benefits and goals that the government wants to achieve. In addition, for maximum benefits to be generated, the DGT should collaborate with several partners from various sectors. One of the parties that must be included in the collaboration are the academics. Academics should play a role as providers of input to the DGT regarding the prevailing theory. The following is a statement of an academic regarding the important role of academics:

"The role of academics is important because the research is also carried out by academics. If for example, the drive behind this is business, there will be no innovation unless there is revenue. But if you involve academics, you must make things like this; someone must be a dreamer, the government will be the implementer, the user." (In-depth interview with a lecturer at the Faculty of Computer Science, Universitas Indonesia, 20 November 2019).

This form of cooperation is not only technical but could also be in the form of providing recommendations, studies, and theoretical input on the design of implementing blockchain technology in the VAT system in Indonesia. With the synergy in the cooperation between the government and academics, the government will obtain an in-depth view of the blockchain technology so that its application in the e-Invoice system will run effectively and efficiently.

\subsubsection{Practitioners}

The DGT cannot implement a policy or decision on its own. It requires support from government parties or agencies outside the DGT. Outside the DGT, government parties that have higher authority include the President and the Minister of Finance. The following is a statement from the Public Policy and Government Relations Manager of OnlinePajak as a tax practitioner regarding the support from external parties that have a higher authority than DGT:

"If you really want to apply blockchain technology, then we have to approach the highest leadership, for example the Minister of Finance or the President and explain that this technology is important to develop." (In-depth interview with an informant at OnlinePajak, 3 December 2019). 
Tax practitioners argue that the support of parties with higher authority, such as the President and Minister of Finance, holds an important role in implementing blockchain technology in the VAT system in Indonesia. This is because the application of the technology by DGT is designed to be nation-wide. Therefore, the role and intervention of state leaders will contribute to the development and application of blockchain technology. In addition, the most important challenge in adopting blockchain technology is how to establish regulations for the implementation of this technology [6]. This is because laws and regulations can affect the speed of the development of this technology. The following is a statement of a taxation practitioner regarding the importance of the regulatory process:

"Regulations are important, regulations are not as easy as we imagine. Blockchain technology is something that is complicated, so yes, how can we simplify those already complicated words into rules that are easily understood by everyone, even ordinary people." (In-depth interview with an informant at OnlinePajak, 3 December 2019).

Blockchain technology is a technology that is not too familiar among the public, therefore the DGT needs to make regulations that are easily understood by all parties, especially taxpayers. In addition, other tax practitioners think that infrastructure is an important factor that must be taken into consideration if the government is to apply blockchain technology in the VAT system. The following is a statement of the Tax Managing Partner RSM Indonesia as a taxation practitioner regarding this matter:

"Now the most important thing is the internal infrastructure, right? If the taxpayers just need to follow the procedure, whatever the form, there is nothing they can do. But if you want to issue a policy, whatever the form is-now if the system is still Output Tax and Input Tax, maybe what is required is information about who the seller is; someone is selling so he/she will declare it. This is the Tax ID Number, of the TE, it is clear who the transaction counterparty is and only input is left in the system. So, the system must be developed." (In-depth interview with an informant at RSM Indonesia, 21 November 2019).

This statement underlines the importance of the DGT's internal infrastructure and, thus, should be carefully considered. Infrastructure is important because the taxpayer as a user only makes use of the infrastructure provided by the government. Thus, if the DGT wants to implement blockchain technology in the VAT system, it should not be difficult for taxpayers to access it. The infrastructure designed to implement blockchain technology in the e-Invoice system in Indonesia must, of course, prioritize taxpayer data security.

The distributed blockchain technology system is one of the reasons why this technology has a high level of security. However, it is precisely the distributed systems that should be underlined and scrutinized. Blockchain technology allows all nodes to connect and view the information data entered the blockchain technology network. This can raise the concerns of TE regarding data security and identity because loopholes in the technology leading to data leakage remain, even though, in the context of blockchain technology, this is difficult. Concerns regarding data hacking in blockchain technology were also expressed by a blockchain practitioner in Indonesia as follows:

"Moreover, in Indonesia there is no GDPR (General Data Protection Regulation) and PDPA (Personal Data Protection Action). We don't have any personal data regulations, so if our data is sold by cellular providers who offer advertisements via Short Message Service (SMS), it's violating the PDPA. I don't know why until now we still don't have PDPA. It's still low level; the one that is already high level is the GDPR of the Europe Union. It is truly affective; if our data is in the hands of a company and we as the user want the data to be deleted, then it must be deleted. We are users who don't have PDPA and it is still low level, I'm worried, because now we are scrutinized by many companies from outside Indonesia. It's crucial. The government should pay attention to that." (In-depth interview with an informant at Blocktogo, 29 November 2019). 
Currently, Indonesia does not have a GDPR or General Data Protection Regulation and PDPA (Personal Data Protection Action). In fact, data security regulations such as the GDPR and PDPA are very crucial in today's digital era. Regulations regarding the security of personal data in Indonesia are currently very low. If parties were to secretly sell or use the data of Indonesians for their own interests, Indonesians could not sue them because there is no legal basis. In this digital era, it is very easy to collect personal data from the internet. Therefore, TE data security must have special attention from the government if blockchain technology is to be implemented in the VAT system in Indonesia in the future.

\subsubsection{Association and Organization}

In following the procedure to implement new technology, the DGT must go through several stages. Infrastructure is one of the parts involved in the procedure. The Chairman of the Indonesian Blockchain Association asserted that if the government wants to implement blockchain technology in the VAT system, particularly for e-Invoice, the government must pay special attention to the infrastructure readiness, human resource readiness, commitment to change, and proper regulations. In addition, collaboration with various parties is also something that must be considered because consensus from the management is greatly needed.

It is crucial to consider the network infrastructure because the taxpayer, as a user, only makes use of the infrastructure provided by the government. Thus, if the DG wants to implement blockchain technology in the VAT system, it is important that taxpayers should not face difficulties when accessing it. The following is a statement from the Chairman of Indonesian Blockchain Association regarding the importance of preparing a blockchain network:

"The most important thing is to prepare a blockchain network that the government wants to be used widely. This can be done in two ways. The first is to use the existing infrastructure network or create a new blockchain infrastructure network." (In-depth interview with an informant at the Indonesian Blockchain Association, 6 December 2019).

The blockchain technology network that the government is to prepare does not have to be fixated on the existing infrastructure. Instead, the government should adjust the infrastructure to their needs. As a new technology that has never been applied before, blockchain technology has complex and sensitive technical aspects. Therefore, it is important to have a secure and well-developed network infrastructure. Regarding how the DGT should maintain security and anticipate data hacking, here are the views of a resource person from the Indonesian Blockchain Network:

"At their levels, I think the DGT have to build-out own blockchain because I think Indonesia has the ability to do it. This is the data of Indonesian people, right, so don't take a platform from abroad. It's okay to test it, but until the deployment execution, our huge data will be taken by another party. If I'm not mistaken, there is also a classification that the data cannot be handled by external parties; this data is certainly quite crucial, especially taxation data. Of course, if they can, the source will be local to maintain state data too." (In-depth interview with an informant at the Indonesian Blockchain Network, 29 November 2019).

The above statement explains that to create applications or systems, it would be better if the DGT made its own blockchain technology system without any interference from outside parties related to TE data recording. Cooperation with external parties will still be possible and useful, but not in running the entire business process in the future. Blockchain technology is claimed to be a powerful technology in recording transactions effectively and efficiently and, thus, will be able to produce accurate, reliable, and relevant information. In addition, blockchain technology also has enormous potential in terms of reducing tax avoidance and tax evasion and even the risk of tax fraud.

The use of blockchain technology for taxation, especially for a Value Added Tax, allows internal parties, external parties, and tax officials involved in the blockchain network to see the transactions 
that occur and the potential amount of VAT to be generated. Thus, if blockchain technology is applied to the VAT system, the avoidance of VAT can be reduced optimally because all data are presented transparently and are accessible to the parties in the blockchain because it is mutually validated. Blockchain technology also has the potential to execute smart contracts, including taxation. VAT payable could automatically be paid if it was stated in the agreed upon contract.

Blockchain technology, when applied to VAT, will allow real time VAT recording of the parties involved, in particular sellers and buyers. The copy of the sales-purchase data will be the same between the seller and the buyer for the same transaction. The sellers and buyers will not be able to commit fraud, by, for example, changing the quantity and price of a transaction with the aim of avoiding or embezzling VAT. With the view only feature, tax officials/authorities will be able to access and monitor the movement of sales transactions in real time, facilitate tax collection, and this will certainly encourage tax compliance.

\section{Conclusions}

Blockchain technology can be applied to VAT data that is safe to distribute, namely the TISN. The TISN system based on blockchain technology will make the submission of the TISN from the DGT to the TE faster and more efficient. In addition, the transactions of the TISN can also be monitored and tracked directly by the DGT. The type of blockchain technology that can be applied in the TISN system based on blockchain technology is a permissioned private blockchain, which allows the DGT to run a private but still customizable blockchain system where the DGT can determine which parties are to be nodes and the extent of authority of those parties have in the blockchain technology network.

The implication of this research in conducting a design related to the application of blockchain technology in VAT systems is that the government must pay attention to the characteristics of blockchain technology. The government should analyze what problems in the VAT system could be addressed by the technology. This is because blockchain technology could provide significant benefits when implemented in the right system. In addition, the government should provide an opportunity for academics, businesses, and other parties to collaborate with the government to build the right blockchain technology architecture in the VAT system in Indonesia. Collaboration with external parties who are experts in the field will provide new perspectives and input for the government. Thus, the government will be able to develop a VAT system based on blockchain technology that is effective and efficient.

The application of blockchain technology in the VAT system could have implications for the optimization of the electronic VAT system, improve the user experience of taxpayers using the VAT electronic system, assist the analysis of the national economy by making the data related to the VAT clear and auditable, and enhance the transparency of VAT transactions. The implementation of blockchain technology in the VAT system could have very broad implications, not only for the taxation sector but also for the national economy.

Therefore, the government should be open to blockchain technology and its use in the VAT system. Blockchain technology has great potential to help the government create a more effective and efficient VAT technology system. The government, especially the DGT as the tax authority, must understand how to apply blockchain technology from the basic to the complex level. An incomplete understanding could lead to misconceptions regarding the benefits and applications of blockchain technology. Apart from the readiness of human resources, it is also necessary to prepare business models, infrastructure, data security, governance, and to develop smart contract features.

Academics play a role as partners who can provide input that on the benefits, goals, and risks of DGT. This form of cooperation could be in the form of providing recommendations, producing studies, and theoretical input on the design of implementing blockchain technology in the VAT system. Tax practitioners argue that the support of parties with higher authority, such as the president and the minister of finance, has an important role in implementing blockchain technology in the VAT system. 
This is because easily understood laws and regulations (especially regarding data security) can affect how fast blockchain technology can develop.

Finally, representatives from the association asserted that if the government is to implement blockchain technology in the VAT system, particularly for e-Invoices, the government should investigate the infrastructure and human resource readiness, commitment to change, proper regulations, and collaboration with various parties. This is important as consensus from the management is necessary.

Further studies regarding the application of blockchain technology to the VAT system are still greatly needed. We suggest some potential future research opportunities. First, future research could use other frameworks in analyzing the readiness and implementation of blockchain technology in the VAT system. The use of various types of analytical frameworks will provide many benefits that could be used as input in implementing blockchain technology in the VAT system. Second, future researchers could conduct a more comprehensive literature review that discusses the use of blockchain technology in the taxation sector, both concerning its opportunities and challenges.

This literature review will be useful as a means of sharing the knowledge or best practices from blockchain studies from various countries. Third, future studies can further evaluate the readiness of the organization, law, regulation, infrastructure, HR, business model suitability, and governance in implementing blockchain technology in the VAT system. Finally, further research could empirically investigate and evaluate the effectiveness and efficiency of using blockchain in the VAT system, to determine whether it is successful in reducing the costs and risks of tax collection, increasing data confidentiality security, and increasing tax revenue from a VAT.

Author Contributions: Conceptualization, M.S.S., A.H.S., and A.H.; writing-original draft, N.D.U.; investigation, N.D.U.; methodology, N.D.U. and A.H.S.; resources, M.S.S.; supervision, M.S.S. and A.H.; validation, A.H.; formal analysis, M.S.S., N.D.U., and A.H.S.; writing—review and editing, A.H.S. All authors have read and agreed to the published version of the manuscript.

Funding: This research received no external funding.

Acknowledgments: The authors acknowledge the Directorate of Research and Development Universitas Indonesia for supporting this study, all the valuable informants who participated in this research, and the three anonymous reviewers for their insightful and constructive feedback.

Conflicts of Interest: The authors declare no conflict of interest.

\section{References}

1. Nagoro, M.W. Revolusi Industri 4.0, Dari Mesin Uap Hingga DJP Online. 2019. Available online: https://www. pajak.go.id/id/artikel/revolusi-industri-40-dari-mesin-uap-hingga-djp-online (accessed on 26 September 2019).

2. OECD. Tax Administration 2017: Comparative Information on OECD and Other Advanced and Emerging Economies; OECD Publishing: Paris, France, 2017.

3. Kristiaji, B.B. Mengukur Kinerja Penerimaan PPN. 2016. Available online: https://news.ddtc.co.id/mengukurkinerja-penerimaan-ppn-6400 (accessed on 22 September 2019).

4. Choi, B.-G.; Jeong, E.; Kim, S.-W. Multiple Security Certification System between Blockchain Based Terminal and Internet of Things Device: Implication for Open Innovation. J. Open Innov. Technol. Mark. Complex. 2019, 5, 87. [CrossRef]

5. Al-Saqaf, W.; Seidler, N. Blockchain technology for social impact: Opportunities and challenges ahead. J. Cyber Policy 2017, 2, 338-354. [CrossRef]

6. Wibowo, S.; Sandikapura, T. Improving Data Security, Interoperability, and Veracity using Blockchain for One Data Governance, Case Study of Local Tax Big Data. In Proceedings of the 2019 International Conference on ICT for Smart Society (ICISS), Bandung, Indonesia, 19-20 November 2019. [CrossRef]

7. Beck, R.; Müller-Bloch, C.; King, J.L. Governance in the Blockchain Economy: A Framework and Research Agenda. J. Assoc. Inf. Syst. 2018, 19, 1020-1034. [CrossRef]

8. Werner, F.; Basalla, M.; Schneider, J.; Hayes, D.; Vom Brocke, J. Blockchain Adoption from an Interorganizational Systems Perspective-A Mixed-Methods Approach. Inf. Syst. Manag. 2020. [CrossRef] 
9. Kosmarski, A. Blockchain Adoption in Academia: Promises and Challenges. J. Open Innov. Technol. Mark. Complex. 2020, 6, 117. [CrossRef]

10. Risius, M.; Spohrer, K. A Blockchain Research Framework. Bus. Inf. Syst. Eng. 2017, 59, 385-409. [CrossRef]

11. Ølnes, S.; Ubacht, J.; Janssen, M. Blockchain government: Benefits and Implications of Distributed Ledger Technology for Information Sharing. Gov. Inf. Q. 2017, 34, 355-364. [CrossRef]

12. Mosteanu, N.R.; Faccia, A. Digital Systems and New Challenges of Financial Management-Fintech, XBRL, Blockchain and Cryptocurrencies. Qual. Access Success 2020, 21, 159-166.

13. Clohessy, T.; Acton, T. Investigating the influence of organizational factors on blockchain adoption: An innovation theory perspective. Ind. Manag. Data Syst. 2019, 119, 1457-1491. [CrossRef]

14. Gorkhali, A.; Li, L.; Shrestha, A. Blockchain: A literature review. J. Manag. Anal. 2020, 7, 321-343. [CrossRef]

15. Alkhodre, A.; Ali, T.; Jan, S.; Alsaawy, Y.; Khusro, S.; Yasar, M. A Blockchain-based Value Added Tax (VAT) System: Saudi Arabia as a Use-Case. Int. J. Adv. Comput. Sci. Appl. 2019, 10, 708-716. [CrossRef]

16. Solehzoda, A. Information Technologies in the Tax Administration System of VAT. J. Adv. Res. Law Econ. 2017, 8, 1340-1344. [CrossRef]

17. Bock, G. How Blockchain Could Help Fight-Or Even End-VAT Fraud. 2017. Available online: https: //blog.kpmg.lu/how-blockchain-could-help-fight-or-even-end-vat-fraud/ (accessed on 26 August 2019).

18. Tasca, P. Insurance under the Blockchain Paradigm. Business Transformation through Blockchain; Palgrave Macmillan: Cham, Switzerland, 2018; pp. 273-285.

19. Faccia, A.; Mosteanu, N.R. Tax Evasion, Information System and Blockchain. J. Inf. Syst. Oper. Manag. 2019, 13, 65-74.

20. PwC Netherlands. Blockchain Helps Prevent VAT Fraud. 2017. Available online: https://www.pwc.nl/en/ topics/digital/clientcases/blockchain-helps-prevent-vat-fraud.html (accessed on 26 August 2019).

21. Gupta, M. Blockchain for Dummies, IBM Limited ed.; John Wiley \& Sons, Inc.: Hoboken, NJ, USA, 2017.

22. Bambara, J.J.; Allen, P.R. Blockchain: A Practical Guide to Developing Business, Law, and Technology Solutions; McGraw-Hill Education: New York, NY, USA, 2018.

23. Laurence, T. Blokchain for Dummies; John Wiley \& Sons, Inc.: Hoboken, NJ, USA, 2017.

24. Schenk, A. Value Added Tax a Model Statute and Commentary; American Bar Association: Chicago, IL, USA, 1989.

25. Janssen, M.; Weerakkody, V.; Ismagilova, E.; Sivarajah, U.; Irani, Z. A framework for analysing blockchain technology adoption: Integrating institutional, market and technical factors. Int. J. Inf. Manag. 2019, 50, 302-309. [CrossRef]

26. Wijaya, D.A.; Darmawan, O. Blockchain, Dari Bitcoin untuk Dunia; Jasakom: Jakarta, Indonesia, 2017.

27. Lin, I.-C.; Liao, T.-C. A Survey of Blockchain Security Issues and Challenges. Int. J. Netw. Secur. 2017, 19, 653-659. [CrossRef]

28. Shrivas, M.K.; Yeboah, T. A Critical Review of Cryptocurrency Systems. Texila Int. J. Acad. Res. 2017, 4, 116-131. [CrossRef]

29. Waluyo. Perpajakan Indonesia; Salemba Empat: Jakarta, Indonesia, 2011.

30. Sukardji, U. Pokok-Pokok PPN Indonesia; Edisi Revisi 2015; PT Raja Grafindo: Jakarta, Indonesia, 2015.

31. Resmi, S. Perpajakan Teori dan Kasus; Edisi 8, Buku 2; Salemba Empat: Jakarta, Indonesia, 2015.

32. Santoso, I.; Rahayu, N. Corporate Tax Management: Mengulas Upaya Pengelolaan Pajak Perusahaan Secara Konseptual-Praktikal; Ortax: Jakarta, Indonesia, 2013.

33. Williams, D. Chapter 6: Value-Added Tax. Dalam V. Thuronyi, Tax Law Design and Drafting; International Monetary Fund: Washington, DC, USA, 1996; Volume 1.

34. Jun, M. Blockchain Government-A Next Form of Infrastructure for The Twenty-First Century. J. Open Innov. Technol. Mark. Complex. 2018, 4, 7. [CrossRef]

35. Martin, S.; Saragih, F.; Setyowati, M.S. E-Readiness of Blockchain Technology in Modernization of Tax Administration in Indonesia. 2019. Available online: https://eudl.eu/doi/10.4108/eai.25-6-2019.2288017 (accessed on 29 October 2020). [CrossRef]

36. Morabito, V. Business Innovation through Blockchain, the $B^{3}$ Perspective; Springer International Publishing AG: Cham, Switzerland, 2017.

37. Yue, Y.; Shyu, J.Z. Blockchain-Based Open Network in Technology Intermediation. In Proceedings of the IEEE International Symposium on Innovation and Entrepreneurship (TEMS-ISIE), Hangzhou, China, 24-29 October 2019; pp. 1-7. [CrossRef] 
38. Gates, M. Blockchain: Ultimate Guide to Understanding Blockchain, Bitcoin, Cryptocurrencies, Smart Contracts, and the Future of Money; CreateSpace: Scotts Valley, CA, USA, 2017.

39. Ali, S. Revolusi Industri 4.0 dan Dampaknya Terhadap Pendidikan Akuntansi di Indonesia; Badan Penerbit Fakultas Ekonomi Universitas Gadjah Mada: Yogyakarta, Indonesia, 2020.

40. Deloitte. Blockchain: Enigma, Paradox, Opportunity. 2016. Available online: https://www2.deloitte. com/content/dam/Deloitte/uk/Documents/Innovation/deloitte-uk-blockchain-full-report.pdf (accessed on 7 November 2020).

41. Pedersen, A.B.; Risius, M.; Beck, R. A Ten-Step Decision Path to Determine When to Use Blockchain Technologies. MIS Q. Exec. 2019, 18, 3. [CrossRef]

42. Swan, M. Blockchain: Blueprint for a New Economy; O’Reilly Media, Inc.: Sebastopol, CA, USA, 2015.

Publisher's Note: MDPI stays neutral with regard to jurisdictional claims in published maps and institutional affiliations.

(C) 2020 by the authors. Licensee MDPI, Basel, Switzerland. This article is an open access article distributed under the terms and conditions of the Creative Commons Attribution (CC BY) license (http://creativecommons.org/licenses/by/4.0/). 